\title{
Strategy for surgical treatment of acute thoracic empyema in adults
}

\author{
Makoto Endoh, Satoshi Shiono \\ Department of Thoracic Surgery, Yamagata Prefectural Central Hospital, Yamagata, Japan \\ Contributions: (I) Conception and design: Both authors; (II) Administrative support: Both authors; (III) Provision of study materials or patients: \\ Both authors; (IV) Collection and assembly of data: Both authors; (V) Data analysis and interpretation: Both authors; (VI) Manuscript writing: Both \\ authors; (VII) Final approval of manuscript: Both authors. \\ Correspondence to: Makoto Endoh, MD. Department of Thoracic Surgery, Yamagata Prefectural Central Hospital, 1800, Ooazaaoyagi, Yamagata 990- \\ 2292, Japan. Email: m-endoh@ypch.gr.jp.
}

\begin{abstract}
This review summarized the surgical management of empyema and treatment strategy by comparing the results of surgical and non-surgical therapies for empyema. Despite improvement in healthcare practices, mortality from pleural infection remains high. Treatment for thoracic empyema depends on its stage at diagnosis, and suggested options involve the administration of antibiotics and drainage of pleural effusion. Prevalence of patients requiring either fibrinolytic treatment into the thoracic cavity or surgical decortication was also reported. In surgical treatment for empyema, "drainage and dilatation of the lungs" is a basic concept. Thoracoscopic decortication, which is currently popular, consists of evacuation by suction, disruption of fibrous pleural septations and peeling off adhesions until the empyema cavity becomes a single space. Chest tubes were inserted at the end of the procedure through separate incisions for thoracoports. The advantages of thoracoscopic surgery are visualization of the entire thoracic cavity, removal of the purulent pleura, and accurate placement of the thoracic drain with less surgical trauma, improved postoperative pain control, less respiratory compromise and reduction in postoperative complications including 30-day mortality. Prompt response and initial surgical treatment to empyema could reduce the severity and complications, shorten the hospital stay, and reduce medical costs.
\end{abstract}

Keywords: Acute thoracic empyema; treatment strategy; thoracoscopic surgery

Received: 13 March 2020. Accepted: 06 April 2020; Published: 25 February 2021.

doi: $10.21037 /$ ccts.2020.04.02

View this article at: http://dx.doi.org/10.21037/ccts.2020.04.02

\section{Introduction}

Acute thoracic empyema is defined as active inflammation and effusion between the parietal and visceral pleural space. Despite improvement in healthcare practices, mortality from pleural infection remains high (1). Guidelines state that treatment for thoracic empyema depends on its stage at diagnosis (2-4). Suggested treatment involves the administration of antibiotics and drainage of pleural effusion (2-5).

A recent systematic review of 134 articles (a total of 227,898 patients) reported that patients with thoracic empyema had long inpatient hospital stay [median 19 days, interquartile range (IQR) 13-27 days], and the median (IQR) in hospital or 30 -day mortality was $4 \%(1-11 \%$, totaling 179,031 patients) (6). The prevalence of patients requiring either fibrinolytic treatment (median $31 \%$, IQR $17-57 \% ; 30,071$ patients) or surgery (median $20 \%$, IQR $1-32 \% ; 37,330$ patients) was also reported. Empyema should be addressed promptly. Prompt response can reduce the severity and complications, shorten the hospital stay, and reduce medical costs $(7,8)$.

For drainage of pleural effusion, some trials proceeded directly to surgical management if the initial pleural fluid aspirate was thick pus or there were extensive loculations on imaging $(7,9,10)$. However, to the best of our knowledge, 
there is currently no clear consensus on the most effective method: primary surgical intervention versus non-surgical management.

Thus, this review aimed to introduce surgical management for empyema and reconcile the treatment strategy by comparing the results between surgical and nonsurgical therapies for empyema.

\section{Treatment strategy}

Treatment of empyema includes administration of antibiotics, thoracic drainage with closed tubing thoracostomy, intrathoracic administration of fibrinolytic agents, and surgery.

The British Thoracic Society Pleural Disease Guideline 2010 indicated selecting patients for pleural fluid drainage in pleural infection (2). Patients with frankly purulent, turbid, or cloudy pleural fluid on sampling by thoracentesis should receive prompt chest tube drainage of the pleural space. The presence of organisms identified by positive Gram stain and/or culture from a non-purulent pleural fluid sampling indicates pleural infection and should lead to prompt chest tube drainage (2).

The mortality benefit from intrathoracic administration of fibrinolytic agent for empyema has not been reported; thus further study was needed to explore this effect on mortality (2,6,11-14). This procedure is a known possible cause of pneumothorax or hemothorax $(15,16)$.

Patients who fail chest tube drainage are also additional candidates for surgical drainage. Delays in initiating surgical drainage when indicated prolongs hospital stay and worsens clinical outcome. The goals in selecting a surgery are to rapidly establish an effective pleural drainage and to promote lung re-expansion to obliterate the empyema space.

\section{Operative indication}

In surgical treatment for empyema, "drainage and dilatation of the lungs" is a basic concept. Pneumoniainduced empyema is classified into three stages according to its progression as stage I, parapneumonic effusion with exudative effusion; stage II, fibrinopurulent stage marked by fibrinopurulent effusion; and stage III, chronic organizing stage forming granulation tissue (pleural peel) (3).

Surgery is performed mainly for stages II and III and consists of aspiration of pleural effusion, destruction of the fibrin septum in the pleural cavity and single cavitation, removal of purulent pleural effusion and inflammatory substances, adequate pleural lavage, and placement of drainage tubes. In stage III, additional removal of the thickened pleura and promotion of reinflation are performed.

Patients in whom chest tube drainage was unsuccessful are also candidates for surgical intervention. Conservative treatment of empyema is challenging owing to host factors and factors determining the disease stage, which possibly cause multiplication of the empyema cavities and decreased drainage. If the pleural effusion develops in the multiple loculae of the septum, medical treatment becomes difficult. Performing drainage promptly during thoracoscopic surgery will help improve results.

\section{Operative technique}

Before surgery, chest computed tomography should be performed to obtain anatomical information about the location, size, extent of the empyema, and pleural surface thickness (17).

\section{Video-assisted thoracic surgery (VATS)}

VATS, which is currently popular (18), consists of evacuation by suction, disruption of fibrous pleural septations and peeling off adhesions until the empyema cavity becomes a single space. Chest tubes were inserted at the end of the procedure through separate incisions for thoraco-ports. The advantages of VATS are visualization of the entire thoracic cavity, removal of the purulent pleura, and accurate placement of the thoracic drain with less surgical trauma, improved postoperative pain control, less respiratory compromise and reduction in postoperative complications including 30-day mortality.

However, despite effective placement of drainage tubes, improvement of empyema cannot be achieved if the drain is obstructed. In the past, we have used porous 24-32 Fr tubes; however, they drain pus only through their tips, which should be washed to clear the blockage when occluded. Recently, a drain has been developed with a drainage hole at the tip and a longitudinal groove at the side; this has the advantages of both drains and is useful for drainage of empyema. It is made of silicone and is soft; further, drainage of empyema may have a longer indwelling period, which may reduce pain.

We placed the aforementioned drainage tube on the dorsal side and on the diaphragm (near the pulmonary ligament) at the time of thoracoscopic surgery and another 
drain on the ventral side in cases with extensive empyema.

\section{Open thoracotomy (OT) approach}

In the OT approach, decortication removes fibrous tissue and peels from the parietal and visceral pleura and pus from the pleural cavity (19). Theoretically, complete decortication can improve intrathoracic infection and expand the lungs. However, it should not be performed solely to remove pleural thickening because pleural thickening disappears spontaneously over several months $(20,21)$. In a previous study, improving the numerical value of the respiratory function at discharge and at 6 months had no significant effect on patients with or without residual pleural thickening, although pleural thickening markedly reduced with regard to time at discharge and 6 months (21).

\section{Outcome of surgical treatment for empyema}

\section{Surgical treatment versus non-surgical treatment for empyema}

Recently, three studies using observational large-scale databases also revealed the actual clinical aspects of empyema treatment (Table 1) (22-24).

Of the 17,533 patients treated for empyema in North America from 1987 to 2014 and in Canada from 1996 to 2015, 8,097 (VATS 4585 and OT 3512) in the surgical treatment group and 9436 in the non-surgical treatment group were retrospectively examined for treatment results. The average age of patients was significantly higher in the non-surgical treatment group (61-62 years) than in the surgery group $(53-56$ years) $(\mathrm{P}<0.001)$. The initial treatment success rate was $85 \%$ for VATS, $73 \%$ for OT, and $59 \%$ for non-surgical treatment. The mortality rate was 6-14\% for VATS, $8-20 \%$ for OT, and $21-32 \%$ for nonsurgical treatment $(\mathrm{P}<0.001)$. The relapse rate of empyema was $4 \%$ for VATS, $3-6 \%$ for OT, and $5-9 \%$ for nonoperative treatment.

These studies demonstrated that the surgery group has higher the initial treatment success rate and mortality rate than the non-surgical treatment group although there was age difference and some degree of selection bias. By reducing the burden of patients from surgery and anesthesia, if early surgical intervention can be added to patients who had to be limited to non-surgical treatment, improvement of treatment results for empyema might be expected.

\section{Surgery versus non-surgical treatment in randomized control trials (RCTs)}

There were four RCTs of treatment in stage II/III empyema comparing initial VATS or OT versus chest tube drainage with or without fibrinolytic agents on a total of 208 patients (Table 2) $(7,9,10,25)$.

The treatment success rate was $83-98 \%$ for surgery and $44-86 \%$ for non-surgical treatment. The mean duration of postoperative hospital stay was 8-12 and 13-17 days in the surgery and non-surgery groups. The mortality rate was $2-9 \%$ in the surgery group and $3-11 \%$ in the non-surgery group.

Results of RCTs showed that initial surgical treatment had significantly better outcomes in primary treatment success rate and length of hospital stay than non-surgical treatment in stage II/III empyema, although RCTs were limited by the small sample size, with $20-78$ cases. No significant difference was found in the mortality rate between the two groups because patients who suffered from treatment failure after the chest tube drainage were subsequently treated by surgical drainage and had successful resolution of their empyema.

\section{Outcomes of VATS and open thoracic surgery for empyema}

Expert clinical opinion recommends that VATS should be the first line approach (4). Experts mentioned that VATS and OT are logically parallel.

Two prospective and seven retrospective studies of surgical treatment for stage II and III empyema involved a total of 1,954 patients. VATS and decortication by OT were performed on 1,087 (56\%) and 867 (44\%) patients, respectively (Table 3) (26-34). The treatment success rate was between $38 \%$ and $100 \%$ for VATS and $89 \%$ and $100 \%$ for OT. VATS had shorter operation time (64-153 vs. $137-$ $228 \mathrm{~min}$ ), and shorter postoperative hospital stay (5-16 vs. 7-21 days) than OT. The morbidity rate of treatments was $0-52 \%$ for VATS and $0-57 \%$ for OT, and mortality rate was $0-10 \%$ for VATS and $0-16 \%$ for OT. The relapse rate of empyema was $0-5 \%$ for VATS and $3-12 \%$ for OT.

Compared with OT, VATS for stage II/III empyema could reduce the operative time and length of hospital stay without compromising the primary treatment success rate and complications and mortality after surgery. Initial VATS therapy was indicated not to be inferior to OT and might be tried as an initial surgical intervention for thoracic empyema. 
Table 1 Characteristics of adult patients in retrospective population-based cohort studies of thoracic empyema

\begin{tabular}{|c|c|c|c|c|c|c|c|c|c|c|c|c|c|c|c|}
\hline Study & Year & Study period & Region, country & $\begin{array}{l}\text { Stage of } \\
\text { empyema }\end{array}$ & $\begin{array}{l}\text { Number of } \\
\text { patients }\end{array}$ & $\begin{array}{l}\text { Procedure, number of } \\
\text { patients [\%] }\end{array}$ & Age, years [IQR] & $\begin{array}{l}\text { Time to intervention, } \\
\text { days [IQR] }\end{array}$ & $\begin{array}{c}\text { Single-procedure } \\
\text { treatment success } \\
{[\%]}\end{array}$ & $\begin{array}{l}\text { Initial treatment } \\
\text { success [\%] }\end{array}$ & $\begin{array}{l}\text { Length of } \\
\text { hospital stay, } \\
\text { days [IQR] }\end{array}$ & $\begin{array}{c}\text { 30-day mortality } \\
{[\%]}\end{array}$ & $\begin{array}{l}\text { Total mortality } \\
{[\%]}\end{array}$ & $\begin{array}{l}\text { Readmission for empyema } \\
{[\%]}\end{array}$ & $\begin{array}{l}\text { 90-day re- } \\
\text { intervention [\%] }\end{array}$ \\
\hline \multirow[t]{2}{*}{ Farjah (22) } & 2007 & 1987-2004 & Washington, USA & Stage 2/3 & 4,424 & OP 2,281 [52] & $53 \pm 18$ & NA & NA & NA & $16 \pm 13$ & $123[5]$ & NA & 68 [3] & NA \\
\hline & & & & & & Non-OP 2,143 [48] & $62 \pm 19$ & & & & $13 \pm 11$ & $356[17]$ & & $126[6]$ & \\
\hline \multirow[t]{4}{*}{ Semenkovich (23) } & 2018 & 2009-2014 & New York, USA & Stage $2 / 3$ & 4,095 & VATS 1,313 [32] & 56 [45-69] & $3[1-5]$ & 415 [55] & $648[85]$ & 12 [9-19] & 71 [5] & $83[6]$ & $55[4]$ & $37[3]$ \\
\hline & & & & & & Open 1,219 [30] & 57 [47-69] & $3[1-5]$ & $322[58]$ & $404[73]$ & 15 [10-21] & $83[7]$ & $91[8]$ & $63[6]$ & $45[4]$ \\
\hline & & & & & & $\mathrm{CT} \pm \mathrm{FL} 1,563[38]$ & 64 [52-79] & $2[1-5]$ & $1,030[37]$ & 1,633 [59] & 14 [9-22] & $286[18]$ & $322[21]^{*}$ & 113 [9] & $113[9]$ \\
\hline & & & & & & & $P<0.001$ & $P<0.001$ & & & $P<0.001$ & $P<0.001$ & $P<0.001$ & $P<0.001$ & $P<0.001$ \\
\hline \multirow{3}{*}{ Nayak (24) } & & & & & & Open 2,293 [30] & $56 \pm 16$ & & & & 20 & $107[4]$ & $501[20]$ & $81[3]$ & \\
\hline & & & & & & $\mathrm{CT}_{ \pm} \mathrm{FL} 5,730[38]$ & $61 \pm 17$ & & & & 20 & 698 [11] & $2026[32]^{t *}$ & $281[5]$ & \\
\hline & & & & & & & & & & & & & $P<0.001$ & & \\
\hline
\end{tabular}

${ }^{*}$, in 90-day mortality; **, in 1-year mortality. CT, chest tube; FL, fibrinolytics; IQR, interquartile range; NA, not available; Non-OP, nonoperative treatment; OP, operative treatment; VATS, video-assisted thoracoscopic surgery-

Table 2 Characteristics of patients in randomized controlled trials comparing surgical and medical therapy

\begin{tabular}{|c|c|c|c|c|c|c|c|c|c|c|c|c|c|c|}
\hline Study & Year & Stage of empyema & $\begin{array}{c}\text { Number of } \\
\text { patients }\end{array}$ & $\begin{array}{c}\text { Procedure, number of } \\
\text { patients [\%] }\end{array}$ & $\begin{array}{l}\text { Age, years } \\
\text { [range] }\end{array}$ & Anesthesia, number of patients $[\%]$ & $\begin{array}{l}\text { Duration of tube } \\
\text { drainage, days }\end{array}$ & Number of tubes & $\begin{array}{c}\text { Length of } \\
\text { hospital stay, } \\
\text { days [range] }\end{array}$ & $\begin{array}{l}\text { Primary treatment } \\
\text { success [\%] }\end{array}$ & Mortality [\%] & Complication [\%] & Detail of complication & Costs [USD] \\
\hline \multirow[t]{2}{*}{ Wait (7) } & 1997 & Stage 2/3 & 20 & VATS 11 [55] & $42 \pm 20$ & General anesthesia & $6 \pm 1$ & $2 \pm 0$ & $9 \pm 1$ & 10 [91] & 1 [9] & 0 & Diaphragm damage by CT & $16,642 \pm 2,841$ \\
\hline & & & & CT+FL 9 [45] & $43 \pm 13$ & & $10 \pm 1$ & $2 \pm 1$ & $13 \pm 1$ & $4[44]$ & 1 [11] & 1 [11] & & $24,052 \pm 3,466$ \\
\hline \multirow[t]{3}{*}{ Bilgin (9) } & 2006 & Stage 2/3 & 70 & VATS 35 [50] & 48 [29-68] & Local anesthesia +sedation 29 [83] & NA & NA & 8 [7-11] & 29 [83] & 0 & $1[3]$ & Bronchopleural fistula & NA \\
\hline & & & & $\mathrm{CT}+\mathrm{FL} 35[50]$ & $47[41-69]$ & General anesthesia $6[17]]$ & & & $13[10-18]$ & 22 [63] & $1[3]$ & $1[3]$ & & \\
\hline & & & & & & & & & $P<0.05$ & $P<0.05$ & & & & \\
\hline \multirow[t]{3}{*}{ Bagheri (25) } & 2013 & Stage 2/3 & $40^{*}$ & VATS 20 [50] & 51 [17-72] & NA & NA & NA & $21 \pm 3^{* *}$ & $18[90]$ & 0 & $2[1]$ & $\begin{array}{l}\text { Intraoperative bleeding, wound } \\
\text { infection, atelectasis }\end{array}$ & NA \\
\hline & & & & СТ 20 [50] & 54 [22-65] & & & & $45 \pm 3$ & $12[60]$ & 0 & 1 [1] & & \\
\hline & & & & & & & & & $P=0.001$ & $\mathrm{P}=0.028$ & & & & \\
\hline \multirow[t]{3}{*}{ Ahmed (10) } & 2016 & Stage 2/3 & 78 & OT 43 [55] & $56 \pm 9$ & NA & NA & 2 & $12 \pm 2$ & 42 [98] & 1 [2] & NA & NA & NA \\
\hline & & & & $\mathrm{CT}+\mathrm{FL} 35[45]$ & $56 \pm 8$ & & & 1 & $18 \pm 2$ & 30 [86] & $2[6]$ & & & \\
\hline & & & & & & & & & $P<0.001$ & $P=0.04$ & $P=0.43$ & & & \\
\hline
\end{tabular}

*, randomization after 2 weeks with administration antibiotics; **, hospital stay from the day that empyema was diagnosed. CT, chest tube; FL, fibrinolytics; NA, not available; OT, open thoracotomy; VATS, video-assisted thoracoscopic surgery. 


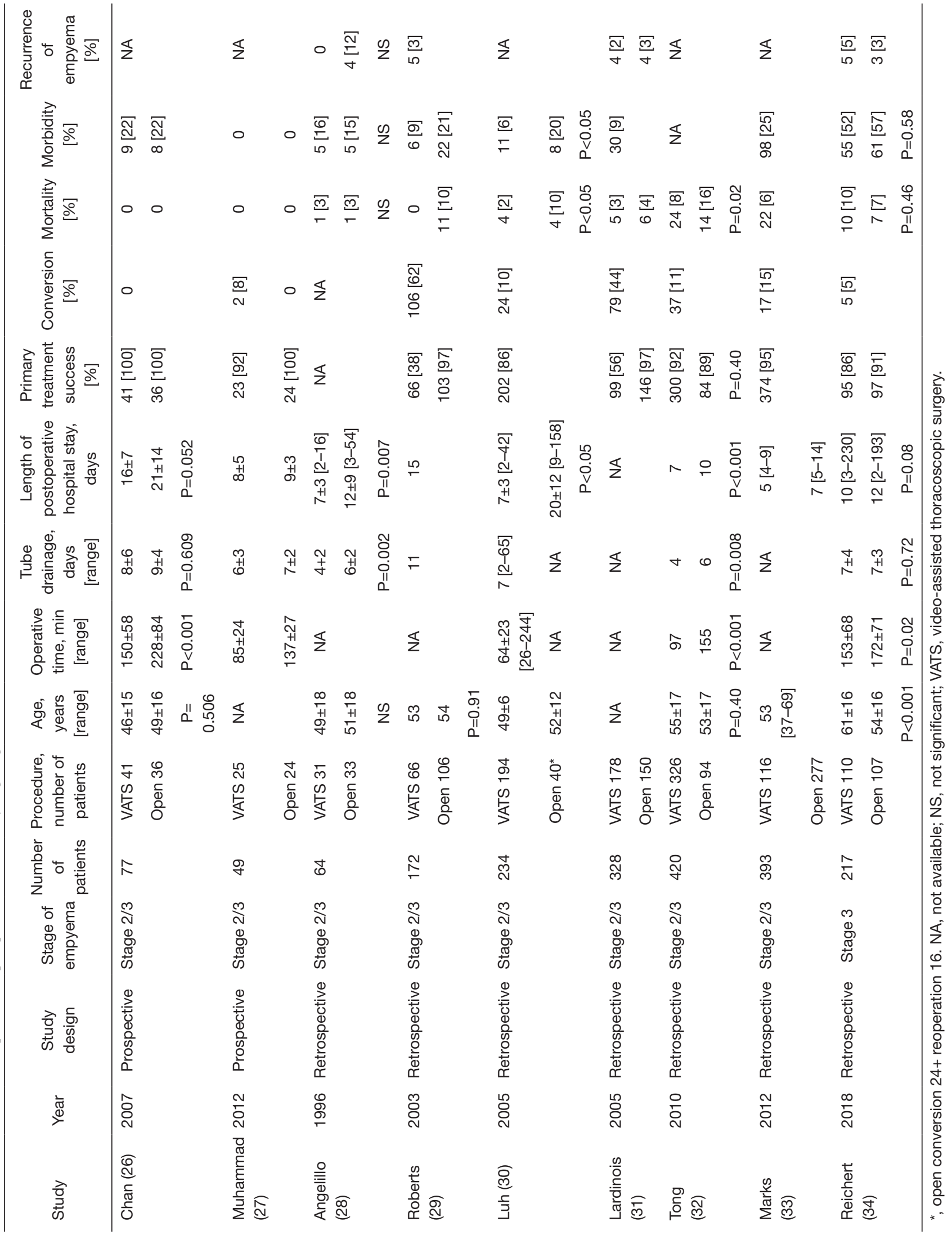



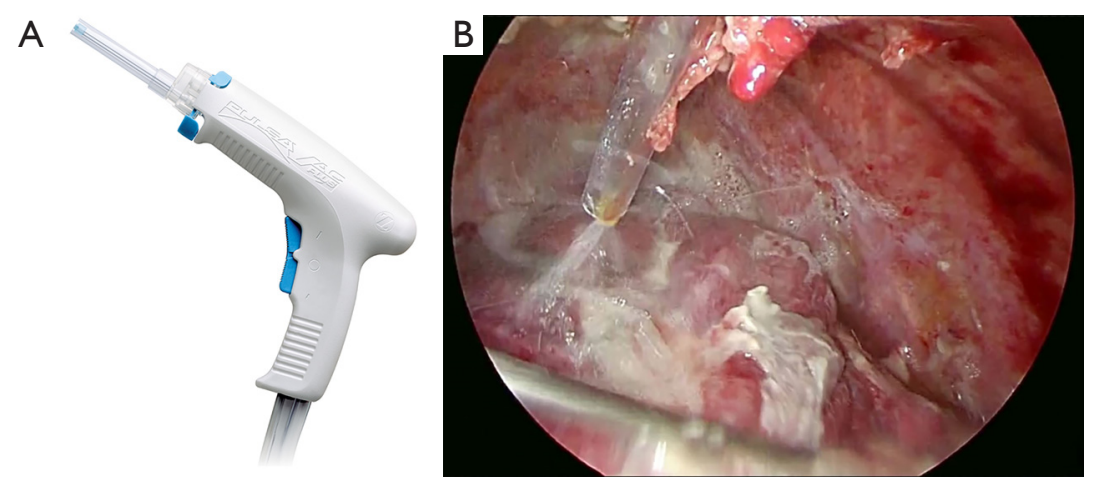

Figure 1 Pulsavac Plus ${ }^{\text {TM }}$ (Zimmer Biomet G.K., Tokyo, Japan). (A) Washing device with pulsation to allow for debridement and suction in the thoracic cavity. The tip of the device is $9 \mathrm{~mm}$ in size; (B) Pulsavac Plus ${ }^{\mathrm{TM}}$ was used for pulse lavage in the purulent thoracic cavity. The lung coated with purulent content was washed with gentle water pressure, and the bony thorax can be washed with powerful water pressure; therefore, the purulent tissue can be removed quickly and efficiently.

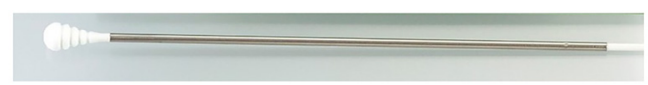

Figure 2 Naruke-type Thoraco-cotton ${ }^{\mathrm{TM}}$ (KENZMEDICO CO., LTD., Saitama, Japan). Cotton stick for the dissection of the tissue and structures in the thorax.

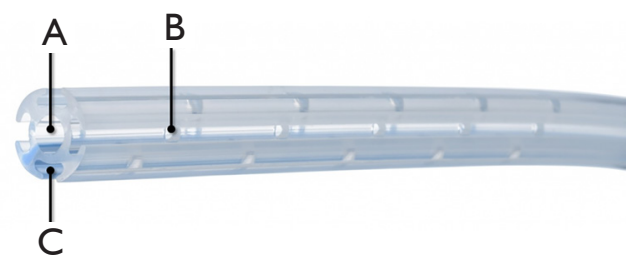

Figure 3 Smart Coaxial Drain (REDAX®, SENKO MEDICAL INSTRUMENT Mfg. CO., LTD., Tokyo Japan). (A) Inner lumen; (B) small pores at the tube tip, 20 holes in total; (C) outer slit.

\section{Discussion}

Dr. Satoshi Shiono: What kind of devices do you use for VATS surgery for acute empyema?

Answer: The surgical procedure for acute empyema was performed using a $1-\mathrm{cm}$ flexible thoracoscope and Pulsavac Plus (Zimmer Biomet G.K., Tokyo, Japan) (Figure 1). The entrapped or septational purulent pleural effusion is curetted and dissected using a grasping forceps of a general thoracoscopic surgical instrument and a cotton swab called the Naruke-type Thoraco-cotton (KENZMEDICO CO., LTD., Saitama, Japan) (Figure 2). After removing the purulent material and decortication, a device called the
Pulsavac was used to wash the thoracic cavity with $10 \mathrm{~L}$ of normal saline (Figure 1). Pulse lavage can be performed in the thoracic cavity using this device; cleaning the thoracic cavity was difficult using conventional techniques. Soft organs, such as the lung, mediastinum or diaphragm can be washed with gentle water pressure, and the bony thorax can be washed with powerful water pressure; therefore, the purulent tissue can be removed quickly and efficiently.

Dr. Satoshi Shiono: When do you remove the chest tubes after surgery?

Answer: The chest drain can be removed after radiological confirmation of successful pleural drainage, that is, on observing a decrease in the size of the pleural collection on the chest radiograph or computed tomography and obtaining objective evidence of infectious resolution, negativity of the pleural effusion culture for bacteria, and decreasing levels of inflammatory markers (e.g., white blood cell count and C-reactive protein levels). Patients are observed for $24 \mathrm{~h}$ after drain removal is routinely performed.

Dr. Satoshi Shiono: Could you show us the picture of the chest tube which you recently use?

Answer: Yes, I could. I have shown the Smart Coaxial Drain (REDAX®, SENKO MEDICAL INSTRUMENT Mfg. CO., LTD., Tokyo Japan) in Figure 3. The drain has a drainage hole at the tip and a longitudinal groove on the side.

\section{Conclusions}

With the surgical treatment of complicated parapneumonic 
effusions and empyema, the treatment period will be shortened and medical cost will be reduced. However, there are only small studies of immediate surgical treatment versus chest tube drainage with fibrinolytics at the start of empyema treatment, but RCTs with increased number of cases are needed to draw definite conclusion.

\section{Acknowledgments}

Funding: None.

\section{Footnote}

Provenance and Peer Review: This article was commissioned by the Guest Editor (Satoshi Shiono) for the series "Empyema" published in Current Challenges in Thoracic Surgery. The article has undergone external peer review.

Conflicts of Interest: Both authors have completed the ICMJE uniform disclosure form (available at https://ccts.amegroups. com/article/view/10.21037/ccts.2020.04.02/coif). The series "Empyema" was commissioned by the editorial office without any funding or sponsorship. SS serves as an unpaid editorial board member of Current Challenges in Thoracic Surgery from September 2019 to August 2021. The authors have no other conflicts of interest to declare.

Ethical Statement: The authors are accountable for all aspects of the work in ensuring that questions related to the accuracy or integrity of any part of the work are appropriately investigated and resolved.

Open Access Statement: This is an Open Access article distributed in accordance with the Creative Commons Attribution-NonCommercial-NoDerivs 4.0 International License (CC BY-NC-ND 4.0), which permits the noncommercial replication and distribution of the article with the strict proviso that no changes or edits are made and the original work is properly cited (including links to both the formal publication through the relevant DOI and the license). See: https://creativecommons.org/licenses/by-nc-nd/4.0/.

\section{References}

1. Bedawi EO, Hassan M, Rahman NM. Recent developments in the management of pleural infection: A comprehensive review. Clin Respir J 2018;12:2309-20.

2. Davies HE, Davies RJ, Davies CW, et al. Management of pleural infection in adults: British Thoracic Society Pleural Disease Guideline 2010. Thorax 2010;65 Suppl 2:ii41-53.

3. Scarci M, Abah U, Solli P, et al. EACTS expert consensus statement for surgical management of pleural empyema. Eur J Cardiothorac Surg 2015;48:642-53.

4. Shen KR, Bribriesco A, Crabtree T, et al. The American Association for Thoracic Surgery consensus guidelines for the management of empyema. J Thorac Cardiovasc Surg 2017;153:e129-46.

5. Redden MD, Chin TY, van Driel ML. Surgical versus non-surgical management for pleural empyema. Cochrane Database Syst Rev 2017;3:CD010651.

6. Cargill TN, Hassan M, Corcoran JP, et al. A systematic review of comorbidities and outcomes of adult patients with pleural infection. Eur Respir J 2019;54:1900541.

7. Wait MA, Sharma S, Hohn J, et al. A randomized trial of empyema therapy. Chest 1997;111:1548-51.

8. Thourani VH, Brady KM, Mansour KA, et al. Evaluation of treatment modalities for thoracic empyema: a costeffectiveness analysis. Ann Thorac Surg 1998;66:1121-7.

9. Bilgin M, Akcali Y, Oguzkaya F. Benefits of early aggressive management of empyema thoracis. ANZ J Surg 2006;76:120-2.

10. Ahmed S, Azam H, Basheer I. Is open decortication superior to fibrinolytic therapy as a first line treatment in the management of pleural empyema? Pak J Med Sci 2016;32:329-32.

11. Maskell NA, Davies CW, Nunn AJ, et al. First Multicenter Intrapleural Sepsis Trial (MIST1) Group. U.K. Controlled trial of intrapleural streptokinase for pleural infection. $\mathrm{N}$ Engl J Med 2005;352:865-74.

12. Tokuda Y, Matsushima D, Stein GH, et al. Intrapleural fibrinolytic agents for empyema and complicated parapneumonic effusions: a meta-analysis. Chest 2006;129:783-90.

13. Rahman NM, Maskell NA, Davies CW, et al. The relationship between chest tube size and clinical outcome in pleural infection. Chest 2010;137:536-43.

14. Rahman NM, Maskell NA, West A, et al. Intrapleural use of tissue plasminogen activator and DNase in pleural infection. N Engl J Med 2011;365:518-26.

15. Ruiz A, Porcel JM, Madroñero AB, et al. Hemothorax following administration of intrapleural alteplase. Respiration 2006;73:715.

16. Chai FY, Kuan YC. Massive hemothorax following administration of intrapleural streptokinase. Ann Thorac Med 2011;6:149-51.

17. Silen ML, Naunheim KS. Thoracoscopic approach to the 
management of empyema thoracis. Indications and results. Chest Surg Clin N Am 1996;6:491-9.

18. Chambers A, Routledge T, Dunning J, et al. Is videoassisted thoracoscopic surgical decortication superior to open surgery in the management of adults with primary empyema? Interact Cardiovasc Thorac Surg 2010;11:171-7.

19. Thurer RJ. Decortication in thoracic empyema. Indications and surgical technique. Chest Surg Clin N Am 1996;6:461-90.

20. Neff CC, vanSonnenberg E, Lawson DW, et al. CT follow-up of empyemas: pleural peels resolve after percutaneous catheter drainage. Radiology 1990;176:195-7.

21. Jiménez Castro D, Díaz G, Pérez-Rodríguez E, et al. Prognostic features of residual pleural thickening in parapneumonic pleural effusions. Eur Respir J 2003;21:952-5.

22. Farjah F, Symons RG, Krishnadasan B, et al. Management of pleural space infections: a population-based analysis. J Thorac Cardiovasc Surg 2007;133:346-51.

23. Semenkovich TR, Olsen MA, Puri V, et al. Current state of empyema management. Ann Thorac Surg 2018;105:1589-96.

24. Nayak R, Brogly SB, Lajkosz K, et al. Outcomes of operative and nonoperative treatment of thoracic empyema: A population-based study. Ann Thorac Surg 2019;108:1456-63.

25. Bagheri R, Tavassoli A, Haghi SZ, et al. The role of thoracoscopic debridement in the treatment of parapneumonic empyema. Asian Cardiovasc Thorac Ann 2013;21:443-6.

26. Chan DT, Sihoe AD, Chan S, et al. Surgical treatment

doi: $10.21037 /$ ccts.2020.04.02

Cite this article as: Endoh M, Shiono S. Strategy for surgical treatment of acute thoracic empyema in adults. Curr Chall Thorac Surg 2021;3:4. for empyema thoracis: is video-assisted thoracic surgery "better" than thoracotomy? Ann Thorac Surg 2007;84:225-31.

27. Muhammad MI. Management of complicated parapneumonic effusion and empyema using different treatment modalities. Asian Cardiovasc Thorac Ann 2012;20:177-81.

28. Angelillo Mackinlay TA, Lyons GA, Chimondeguy DJ, et al. VATS debridement versus thoracotomy in the treatment of loculated postpneumonia empyema. Ann Thorac Surg 1996;61:1626-30.

29. Roberts JR. Minimally invasive surgery in the treatment of empyema: intraoperative decision making. Ann Thorac Surg 2003;76:225-30.

30. Luh SP, Chou MC, Wang LS, et al. Video-assisted thoracoscopic surgery in the treatment of complicated parapneumonic effusions or empyemas: outcome of 234 patients. Chest 2005;127:1427-32.

31. Lardinois D, Gock M, Pezzetta E, et al. Delayed referral and gram-negative organisms increase the conversion thoracotomy rate in patients undergoing video-assisted thoracoscopic surgery for empyema. Ann Thorac Surg 2005;79:1851-6.

32. Tong BC, Hanna J, Toloza EM, et al. Outcomes of videoassisted thoracoscopic decortication. Ann Thorac Surg 2010;89:220-5.

33. Marks DJ, Fisk MD, Koo CY, et al. Thoracic empyema: a 12-year study from a UK tertiary cardiothoracic referral centre. PLoS One 2012; 7:e30074.

34. Reichert M, Pösentrup B, Hecker A, et al. Thoracotomy versus video-assisted thoracoscopic surgery (VATS) in stage III empyema-an analysis of 217 consecutive patients. Surg Endosc 2018;32:2664-75. 